\section{The Effect of Hydrofluoric Acid Concentration and Heat on the Bonding to Lithium Disilicate Glass Ceramic}

Daniel Sundfeld ${ }^{1}$, Lourenço Correr-Sobrinho ${ }^{2}$, Núbia Inocêncya Pavesi Pini' ${ }^{1}$, Ana Rosa Costa ${ }^{2}$, Renato Herman Sundfeld ${ }^{3}$, Carmem Silvia Pfeifer ${ }^{4}$, Luis Roberto Marcondes Martins'

\begin{abstract}
The aim of this study was to evaluate the effects of hydrofluoric acid (HF) concentration and previous heat treatment (PHT) on the surface morphology and micro-shear bond strength ( $\mu \mathrm{SBS})$ of a lithium disilicate glass ceramic (EMX) to resin cement. One hundred four EMX specimens were randomly assigned to two groups $(n=52)$ according to the HF concentration: $5 \%$ and 10\%. A new random distribution was made according to the PHTs $(\mathrm{n}=13)$ : control (no PHT); previously heated $\mathrm{HF}\left(70^{\circ} \mathrm{C}\right)$; previously heated EMX surface $\left(85^{\circ} \mathrm{C}\right)$; the combination of heated $\mathrm{HF}+$ heated EMX surface. The etching time was set at $20 \mathrm{~s}$. All EMX blocks were silanated and received a thin layer of an unfilled resin. Five resin cement cylinders were made on each EMX surface using Tygon tubes as matrices, and then stored for $24 \mathrm{~h}$ at $37{ }^{\circ} \mathrm{C}$. One random etched EMX sample from each group was analyzed using field-emission scanning electron microscopy (FE-SEM). The data were subjected to two-way ANOVA and multiple comparisons were performed using the Tukey post hoc test $(\alpha=0.05)$. For the control groups, $5 \% \mathrm{HF}$ showed statistically lower $\mu \mathrm{SBS}$ values when compared to $10 \% \mathrm{HF}(\mathrm{p}<0.05)$. PHT increased the $\mu \mathrm{SBS}$ values for $5 \% \mathrm{HF}$, yielding statistically similar results to non-PHT 10\% HF $(p<0.05)$. FE-SEM images showed increased glassy matrix removal when PHT was applied to HF 5\%, but not to the same degree as for $10 \% \mathrm{HF}$. PHT has the potential to improve the bond strength of $5 \% \mathrm{HF}$ concentration on lithium disilicate glass ceramic.
\end{abstract}

\author{
'Department of Restorative \\ Dentistry, Piracicaba Dental School, \\ UNICAMP - Universidade Estadual \\ de Campinas, Piracicaba, SP, Brazil \\ ${ }^{2}$ Department of Restorative Dentistry, \\ Dental Materials Division, Piracicaba \\ Dental School, UNICAMP - Estadual \\ de Campinas, Piracicaba, SP, Brazil \\ ${ }^{3}$ Department of Restorative \\ Dentistry, Araçatuba Dental \\ School, UNESP - Univ Estadual \\ Paulista, Araçatuba, SP, Brazil \\ ${ }^{4}$ Department of Restorative \\ Dentistry, Division of Biomaterials \\ and Biomechanics, OHSU \\ - Oregon Health Ct Science \\ University, Portland, OR, USA
}

Correspondence: Prof. Dr. Lourenço Correr-Sobrinho, Avenida Limeira, 901, 13414-903, Piracicaba, SP, Brasil. Tel: +55-19-2106-5200. e-mail: sobrinho@fop.unicamp.br

Key Words: lithium disilicate glass ceramic, hydrofluoric acid, heat treatment, microshear bond strength, FE-SEM analysis

\section{Introduction}

The lithium disilicate glass ceramic has been widely recognized as one of the most reliable restorative materials for indirect restorations indicated for esthetic and functional rehabilitations (1). The ability of being adhesively bonded to tooth substrates, optimal mechanical properties and its natural tooth-like appearance (2-6) are very appealing to dental professionals and patients.

The bond between glass ceramic/resin cement relies on the physical and chemical interaction between them, recognized as one of the key factors for long-term clinical success (7). Physical modification for bonding comprises a ceramic surface treatment that promotes an increased surface area, leading to stronger bond strength values of resin cement to ceramic (8). In addition, the application of a silane solution provides the ability to chemically bond the resin cement to the glass ceramic (9).

Hydrofluoric acid (HF) is considered an efficient surface modification agent that is capable of dissolving the glassy matrix, thereby exposing the embedded lithium disilicate crystals $(8,10-13)$. Consequently, higher bond strength values have been found with the exposure of lithium disilicate crystals due to the increased micromechanical interlocking between the ceramic/resin cement $(8,11)$.
Therefore, the application of hydrofluoric acid followed by a silane solution is the most accepted surface treatment prior to luting a glass ceramic (7).

Because it is very effective, cheap, quick and easy to apply, hydrofluoric acid is very well accepted among dental professionals. In vitro reports have assessed different etching times and concentrations of hydrofluoric acid on the bond strength and mechanical properties when applied onto lithium disilicate glass ceramics $(8,11,12,14-$ 16). Moreover, due to the hazardous nature, lower HF concentrations were evaluated and shown not to perform as well as $7.5 \%$ or higher concentrations regarding bond strength to resin cement (8). Although the manufacturer of IPS e.max Press (Ivoclar Vivadent, Schaan, Liechtenstein), a lithium disilicate glass ceramic with \pm 70 vol\% of crystalline content, recommends that a $4.8 \%$ hydrofluoric acid should be applied for $20 \mathrm{~s}$ before silanization, a consensus of an optimal clinical protocol has not been reached yet (15).

In order to enhance the etching capability, in vitro studies (17-20) have reported increased roughness/ surface area/bond strength when pre-heated solutions (experimental and $48 \%$ hydrofluoric acid) were applied onto zirconia ceramic, demonstrating that heat treatment 
has an influence on the bonding characteristics onto zirconia ceramic substrate.

As 5\% and 10\% are the most commonly adopted hydrofluoric acid concentrations used to etch lithium disilicate glass ceramic, the goal of the present study was to assess the effect of the hydrofluoric acid concentration and its association with previous heat treatments on the surface morphology and bond strength of lithium disilicate glass ceramic to resin cement. The null hypotheses were: 1) HF concentrations would not provide different etching patterns and micro-shear bond strength; 2) the heat treatments would not interfere with the etching patterns or micro-shear bond strength.

\section{Material and Methods}

\section{Lithium Disilicate Glass Ceramic Fabrication}

One hundred and four lithium disilicate glass ceramic blocks (IPS e.max Press, shade LT A2, Ivoclar Vivadent, Schaan, Liechtenstein) (EMX), with dimensions of 8 $\mathrm{mm} \times 8 \mathrm{~mm} \times 3 \mathrm{~mm}$, were fabricated according to the manufacturer's instructions and described in detail in a previous report (8).

\section{EMX Surface Treatments}

After divestment, the ceramic specimens were embedded in polyester resin (Resapol T208, Difibra/ Fiberglass Ltda, Mogi das Cruzes, SP, Brazil) in polyvinyl chloride (PVC) tubes and wet-polished with 1000-, 2500and 4000-grit silicon carbide abrasive papers (Buehler, Lake Buff, IL, USA) to obtain a flat, polished and standardized surface. Then, all specimens were ultrasonically cleaned in distilled water for $20 \mathrm{~min}$.

The EMX specimens were randomly assigned into two groups ( $n=52)$ according to the hydrofluoric acid concentrations: 5\% and 10\% (Fórmula \&t Ação, São Paulo, SP, Brazil). Then, a new random distribution was made according to the previous heating treatments (PHT) ( $n=13)$ : no PHT (control group); PHT of the hydrofluoric acid; PHT of the ceramic surface, and a combination of PHT hydrofluoric acid + PHT EMX surface. These procedures are detailed below.

Control group: the EMX surface was etched with hydrofluoric acid at room temperature $\left(25^{\circ} \mathrm{C} \pm 1\right)$ for 20 $s$ and rinsed with an air-water spray for $30 \mathrm{~s}$ (Fig. 1A).

HF heat treatment: prior to etching, one drop of HF acid was heated to $70^{\circ} \mathrm{C}$ in a pre-calibrated device (Figs. $1 \mathrm{~B}$ and $1 \mathrm{C})$. Then, the heated HF was dropped onto the ceramic surface (Fig. 1D), allowed to react for $20 \mathrm{~s}$ and rinsed with an air-water spray for $30 \mathrm{~s}$.

EMX surface heat treatment: a hot-air stream was perpendicularly applied to the ceramic surface for $1 \mathrm{~min}$ before etching (Fig. 1E). The EMX surface temperature was measured with a digital infrared thermometer (model HT-450, Hikari, Shanghai, China), with a mean temperature of $85 \pm 1{ }^{\circ} \mathrm{C}$ recorded. Then, one drop of HF was poured onto the ceramic surface and maintained for $20 \mathrm{~s}$ (Fig. 1A). The surface was rinsed with an air-water spray for $30 \mathrm{~s}$.

After etching and rinsing, all ceramic specimens were ultrasonically cleaned in distilled water for $20 \mathrm{~min}$ and air-dried. The etching procedures were performed in a ventilated room and the operator was properly protected by using individual protection equipment, protective eyeglass, rubber gloves and a carbon chemical mask (Half Facepiece Reusable Respirator, 6000 series, 3M ESPE, St. Paul, MN, USA).
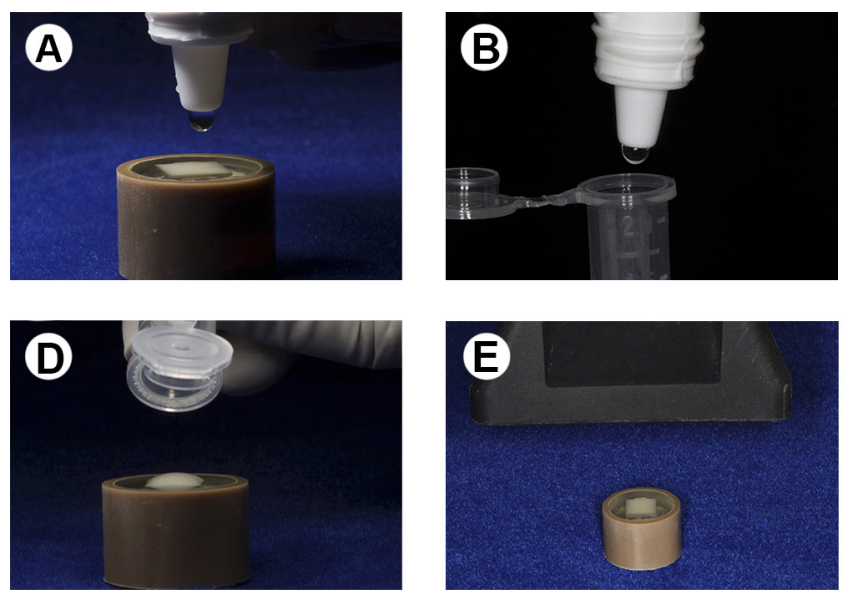

Figure 1. Images of the heating treatment methodology. A: Dispensing one drop of the HF (not previously heated) to the EMX surface. B: One drop of the HF was poured into a $1 \mathrm{~mL}$ eppendorf vial. C: With the lid closed, the eppendorf vial was positioned inside a device calibrated at 70 ${ }^{\circ} \mathrm{C}$ and remained for $1 \mathrm{~min}$. D: The heated HF solution was placed on the EMX surface. E: application of a perpendicular air-heated stream to the EMX surface for 1 min before etching. 
Resin Cement Cylinders Preparation and Micro-Shear Bond Strength ( $\mathrm{S} S B S$ )

One single drop of a silane coupling solution (Monobond-S, Ivoclar Vivadent, Schaan, Liechtenstein) was dispensed onto the EMX surface, rubbed for $15 \mathrm{~s}$ with a disposable microbrush and allowed to air-dry for 1 min. Next, a hot-air stream (Hair dryer, model Tourmaline Ion Cerâmica, Taiff, Varginha, MG, Brazil) was applied perpendicularly for $1 \mathrm{~min}$ in order to increase solvent evaporation, followed by the application of a thin layer of an unfilled resin (Scotchbond Multi Purpose; 3MESPE, St. Paul, MN, USA) that was rubbed for $15 \mathrm{~s}$. Translucent Tygon tubes ( $0.8 \mathrm{~mm}$ diameter $\times 0.5 \mathrm{~mm}$ in height) - five per each ceramic sample were positioned onto the EMX surface and used as matrices. Then, an unfilled resin was light-cured for 20 s using a LED curing device (Valo Cordless, Ultradent Inc., South Jordan, UT, USA) with an irradiance of $1000 \mathrm{~mW} / \mathrm{cm}^{2}$. The base paste of a dual-cured resin cement (Variolink II, shade A2; Ivoclar Vivadent, Schaan, Liechtenstein) was carefully inserted with an \#5 explorer probe into the tygon's tube lumen. After filling all five tygon matrices, the resin cements were light-cured for $40 \mathrm{~s}$.

All specimens were stored in distilled water for $24 \mathrm{~h}$ at $37^{\circ} \mathrm{C}$. A sharp \# 11 scalpel blade was used to section the tygon tubes in order to expose the resin cement cylinders. Optical microscopy analysis at $40 \times$ magnification (Olympus Corp, Tokyo, Japan) was used to confirm that none of the cylinders presented defects/flaws at the bonding interface. The PVC tube was positioned in a $\mu$ SBS device that was properly adapted to a mechanical testing machine (model 4411 ; Instron, Canton, MA, USA). Then, a thin steel wire $(0.2$ $\mathrm{mm}$ in diameter) was looped around the base of each resin cement cylinder and properly aligned with the bonding interface. Each cylinder specimen was subjected to a crosshead speed of $1 \mathrm{~mm} / \mathrm{min}$ until failure. The debonded interfaces were examined under optical microscopy (Olympus Corp) at 40x magnification and the failures were classified as: adhesive; cohesive within ceramic; cohesive within resin cement; and mixed, involving ceramic/adhesive/resin cement.

\section{Field Emission Scanning Electron Microscopy (FE-SEM) Evaluation}

Before the bonding procedures, a random etched EMX specimen, within each group, was selected for a FE-SEM analysis. The specimens were mounted on coded brass stubs and sputter-coated with goldpalladium for $60 \mathrm{~s}$ at $45 \mathrm{~mA}$ (Denton Vacuum Desk II, Moorestown, NJ, USA) and subjected to FE-SEM (FEl Quanta 200 Environmental Scanning Electron Microscope, Hillsboro, OR, USA) analysis operated at $20 \mathrm{kV}$. All images are represented with a $3.038 \times$ magnification (working distance between 10.5 - $11.4 \mathrm{~mm}$ ) with $10 \mu \mathrm{m}$ scale bars.

\section{Statistical Analysis}

The $\mu$ SBS values were obtained in kgf (kilogramforce) and further converted to Megapascals $\left(\mathrm{N} / \mathrm{mm}^{2}\right)$ following the equation below. For each $\mu$ SBS group $(n=12)$, five cylinders were built-up, totaling sixty resin cement specimens. The average of the five cylinders was considered as the $\mu$ SBS value for each EMX block. The data were subjected to two-way analysis of variance and multiple comparisons were performed using the Tukey post hoc test $(\alpha=0.05)$.

$$
B S=\underline{F \times 9.8}
$$

\section{A}

which, BS (bond strength) = Megapascal $; \mathrm{F}=$ kilogram force $(\mathrm{Kgf}) ; 9.8($ Newton) = used to convert the kilogramforce to Newton; $A=$ adhesive interface area $=\pi R^{2}$, where $\pi=3.14$ and $R=$ radius of resin cement cylinder (tygon diameter $=0.8 \mathrm{~mm}, \mathrm{R}=0.4 \mathrm{~mm}$ )

\section{Results}

\section{Micro-shear Bond Strength}

The mean $\mu$ SBS values are summarized in Figure 2. No pretesting failures occurred. Results for two-way ANOVA showed a statistically significant interaction between hydrofluoric acid concentration $\times$ heat treatment $(p=0.000)$. HF concentration $(p=0.000)$ and heat treatment $(p=0.000)$ clearly affected the mean $\mu$ SBS values.

The Tukey multicomparison test demonstrated that 10\% yielded statistically higher $\mu$ SBS when compared to $5 \%$ for the control groups $(\mathrm{p}=0.000)$. For $5 \% \mathrm{HF}$, PHT significantly increased the $\mu$ SBS values, especially for the groups with

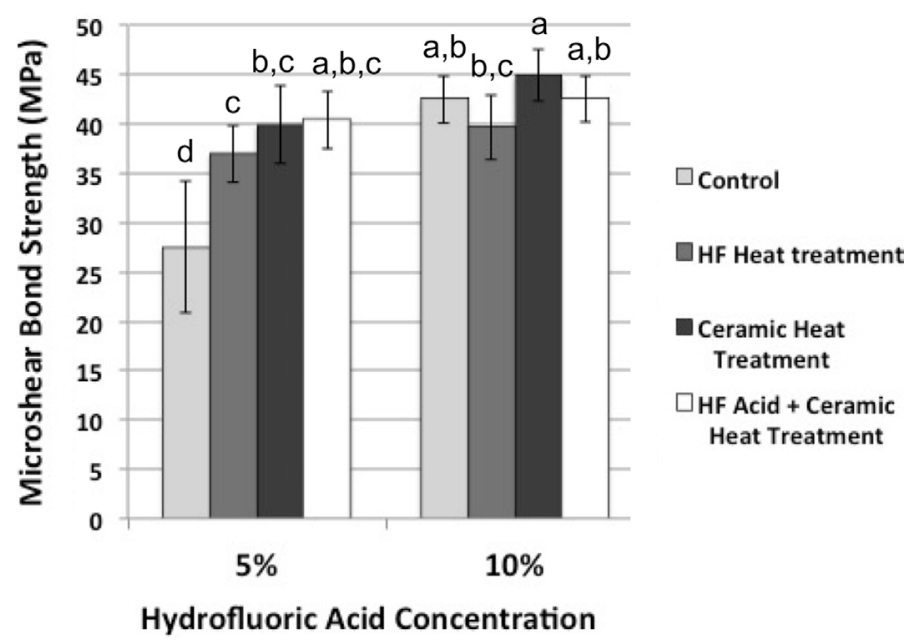

Figure 2. Mean microshear bond strength $(\mathrm{MPa}) \pm$ standard deviation of the evaluated groups. Lowercase letters indicate a significant difference among all groups according to the Tukey multiple comparison post hoc test $(\mathrm{p}<0.05)$. 
PHT EMX ( $p=0.000)$ and PHT HF + EMX ( $p=0.000)$, with these groups not being statistically different from the non-PHT $10 \% \mathrm{HF}$ ( $p=0.6404$ and $p=0.8366$, respectively). For $10 \%$ $\mathrm{HF}, \mathrm{PHT}$ did not significantly influence the $\mu \mathrm{SBS}$, except with PHT EMX, which resulted in a statistically significant difference when compared to the pre-heated $\mathrm{HF}(\mathrm{p}<0.05)$, but was not different from the other groups $(p>0.05)$.

\section{FE-SEM Images}

The EMX etched surface morphologies are represented in Figures 3 and 4. The etching effects of the heating treatment were more pronounced for 5\% HF (Fig. 3). The PHT EMX surface (Fig. $3 \mathrm{C}$ ) and the PHT HF solution + PHT EMX surface (Fig 4D) enhanced the glassy matrix removal and exposure of lithium disilicate crystals when compared to the $5 \%$ control group (Fig. 3A), yielding similar etching patterns when compared to the non-PHT 10\% HF group (Fig. 4). The heat treatment had a slight influence on the etching patterns for $10 \% \mathrm{HF}$ but not to the same extension when compared to $5 \% \mathrm{HF}$.

\section{Failure Modes Analysis}

A descriptive analysis of failure modes is represented in Figure 5. Predominantly adhesive failure was recorded for all groups, except for the 10\% control group, which presented similar percentages of adhesive and mixed failures. No cohesive failures within the ceramic or resin cement were verified.

\section{Discussion}

The present study aimed to assess the influence of HF concentrations and the action of previous heat treatment
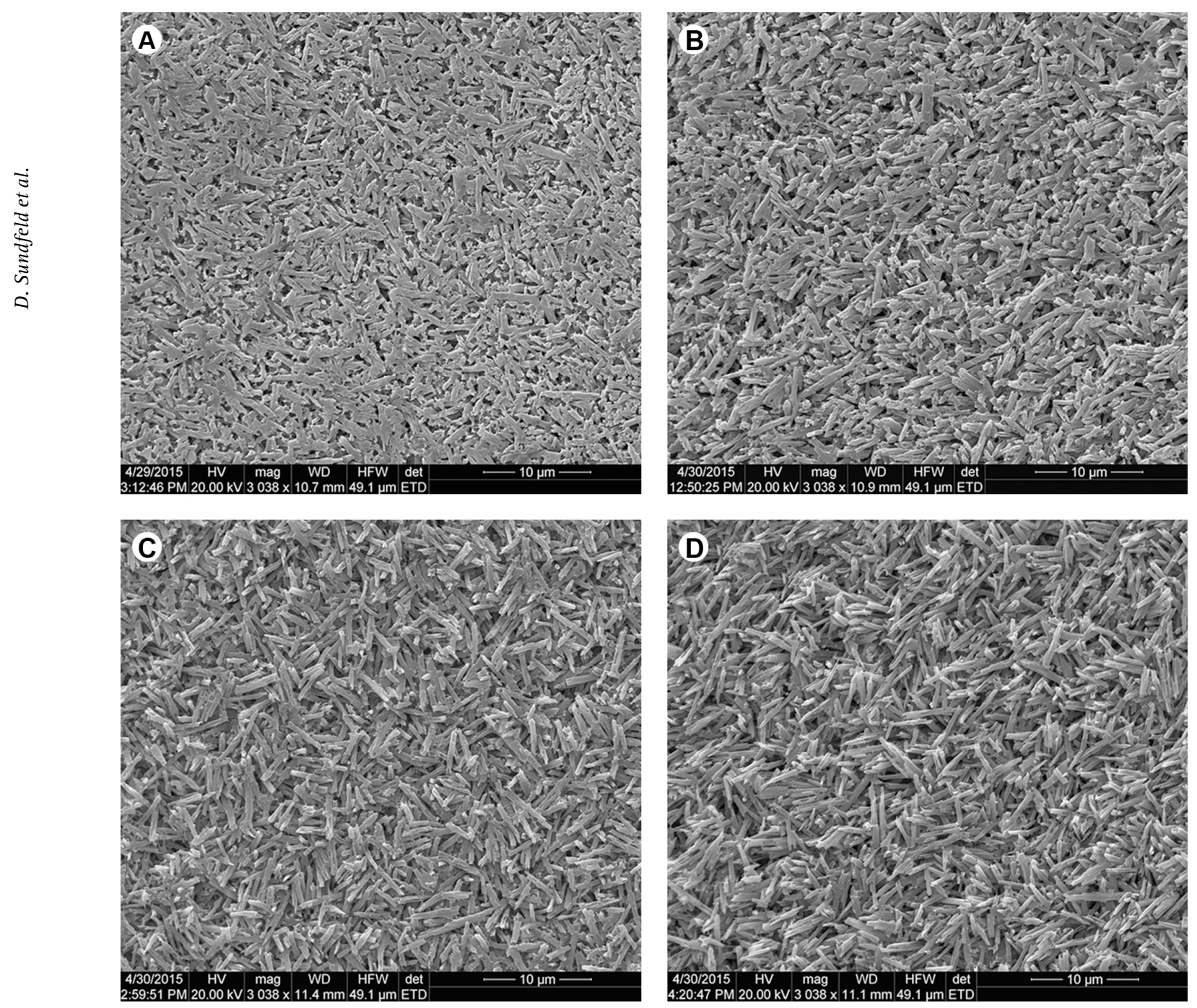

Figure 3. FE-SEM images resulting from acid etching with 5\% hydrofluoric acid (HF) and its respective interactions with heat treatments (PHT). A: control group. B: PHT HF solution. C: PHT EMX surface. D: PHT HF solution + PHT EMX surface. A slight effect of the PHT HF solution was found in image B but an increased glassy matrix dissolution with higher exposure of lithium disilicate crystals was associated with heat treatments in images $\mathrm{C}$ and $\mathrm{D}$. 

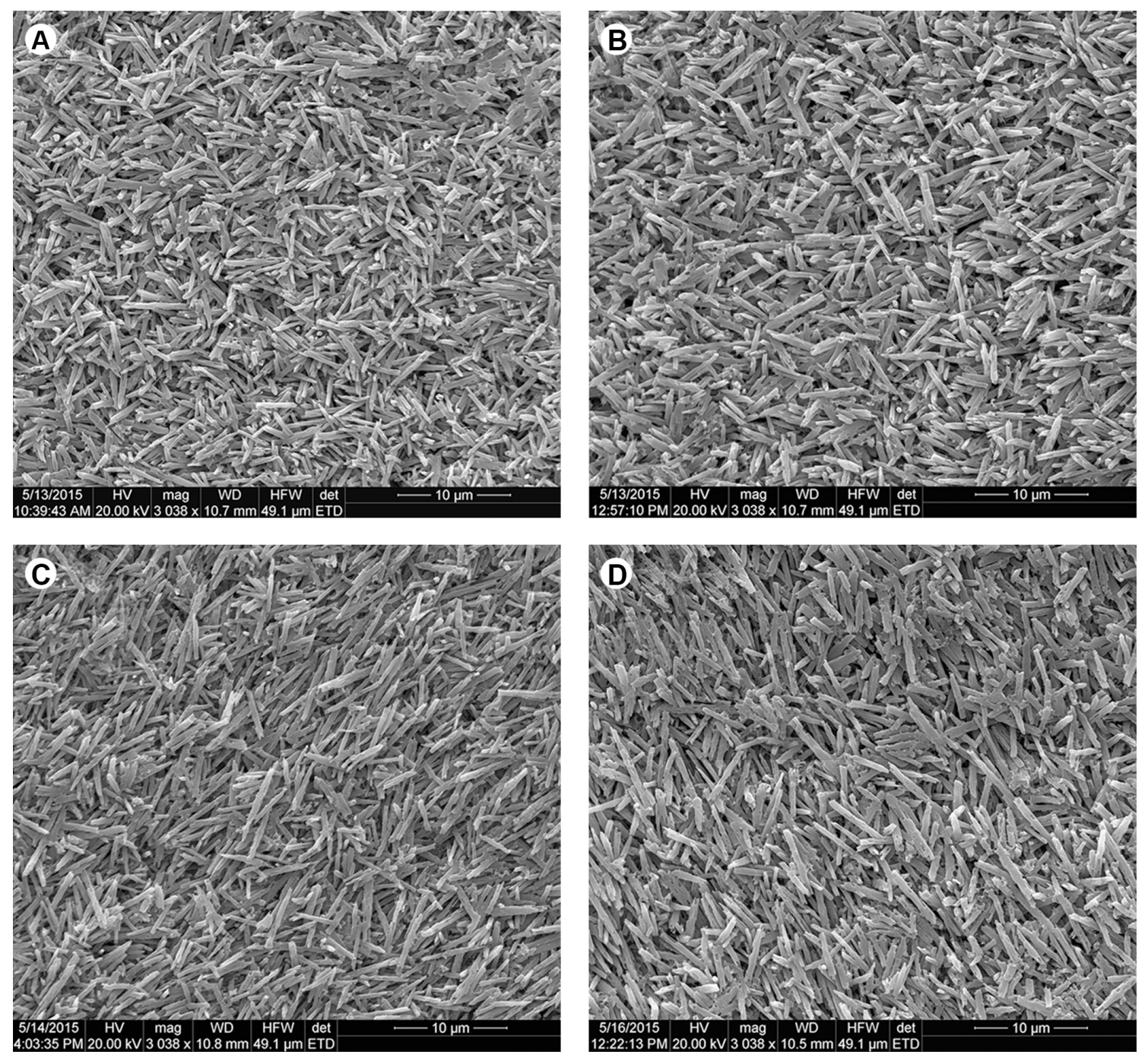

Figure 4. FE-SEM images resulting from acid etching with 10\% hydrofluoric acid (HF) and its respective interactions with heat treatments (PHT). A: control group. B: PHT HF solution. C: PHT EMX surface. D: PHT HF solution + PHT EMX surface. The heating treatments have slightly influenced on the etching pattern, as the heated groups presented higher amount of "loose" lithium disilicate crystals on the EMX surface.

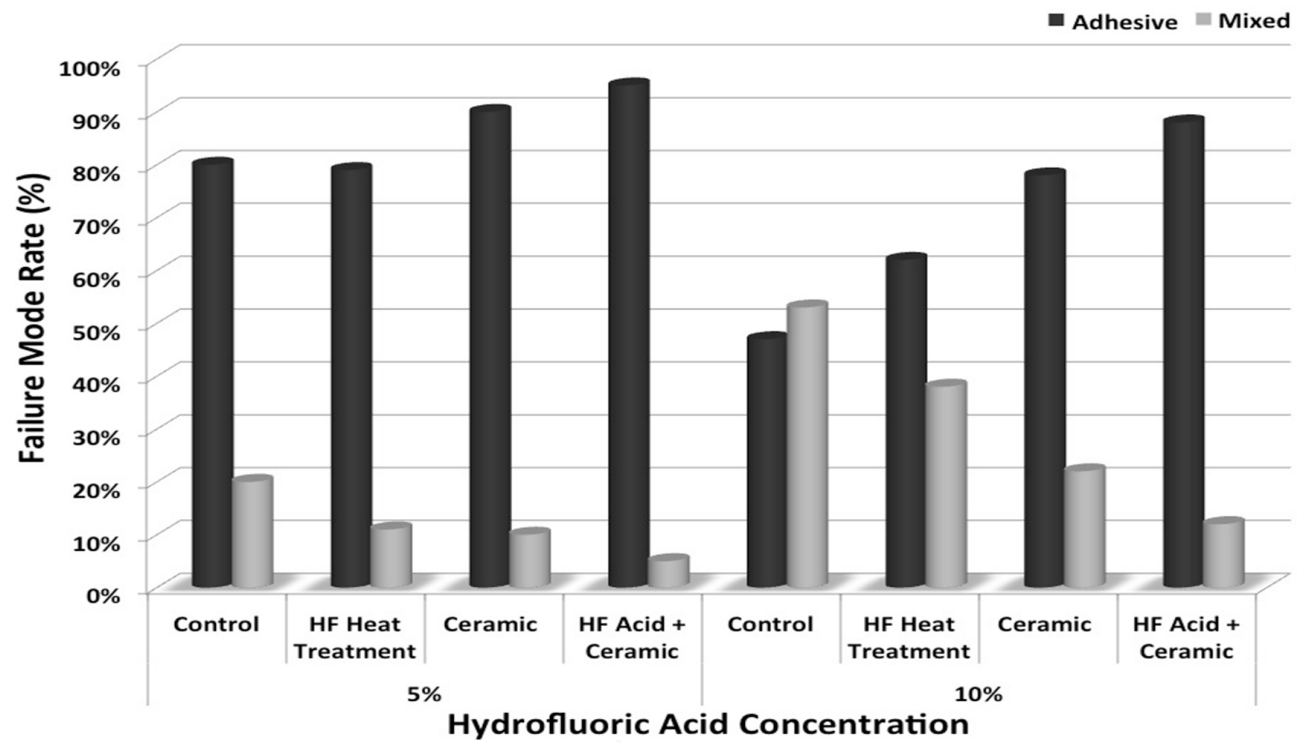

Figure 5. Failure mode analysis of the debonded specimens (\%). 
on the etching pattern/microshear bond strength of lithium disilicate glass ceramic. According to $\mu \mathrm{SBS}$ and FE-SEM analyzes, the evaluated factors played a direct role on the bonding characteristics between EMX to resin cement, rejecting, therefore, both null hypotheses.

The first tested hypothesis was rejected, as 5\% and 10\% $\mathrm{HF}$ resulted in statistically different mean $\mu \mathrm{SBS}$ values and differently affected the etching morphology. $10 \% \mathrm{HF}$ was able to remove a larger amount of glassy matrix and expose more lithium disilicate crystals when compared to $5 \% \mathrm{HF}_{\text {, }}$ due the higher amount of ionized $\mathrm{HF}$ available to react with silicon. HF has the capability to selectively remove the glassy matrix (silicon - $\mathrm{SiO}_{2}$ ) based on the affinity of fluoride to silicon (21). By containing half of the amount of the available ionized $\mathrm{HF}$ in $10 \% \mathrm{HF}, 5 \% \mathrm{HF}$ was not able to remove enough glassy matrix (Figs. $3 \mathrm{~A}$ and $4 \mathrm{~A}$ ) to yield a suitable micromechanical entanglement between EMX/resin cement, which caused the lower $\mu$ SBS values when compared 10\% HF. Sundfeld Neto et al. (8) reported similar findings.

The second tested null hypothesis was partially rejected, since the results for the heating treatments were more expressive for 5\% HF than they were for 10\% $\overrightarrow{\mathrm{H}} \mathrm{HF}$. In general, the initial chemical reaction rate depends on the concentration of the reactants (represented by the letters $a, b$ and $c: a A+b B+c C \rightarrow$ Product), the temperature and pressure (22). In addition, heat acts as a catalyst by strongly speeding up the chemical reaction rate as temperature rises (22). The consequence of the heat treatment is an increased agitative state of the molecules (23), in this case ionized $H F$, which starts to move faster and results in more vigorous collisions with EMX. Then, a greater removal of glassy matrix is achieved for the PHT 5\% HF (Fig. 3), which promoted a better micromechanical entanglement between EMX/resin material and resulted in statistical similar mean $\mu$ SBS values and etching patterns when compared to non-PHT 10\% HF.

For $10 \% \mathrm{HF}$, the heat treatments did not affect the $\mu \mathrm{SBS}$ and FE-SEM analyzes to the same degree when compared to $5 \% \mathrm{HF}$, as the $10 \%$ concentration was already enough to properly etch and remove the glassy matrix at room temperature. Furthermore, the enhanced etching effect achieved with PHT in the 10\% HF group had resulted into a greater amount of "loose" disilicate crystals at the etched surface, indicating an "over-etching" situation (Fig. 4). Those "unattached" crystals might have hindered the micromechanical interlocking of resin materials to the etched pits, which might had lead to increased adhesive failures observed (Fig. 5). Clinicians must be aware that over-etching glass ceramics should not be encouraged, since previous reports found lower bond strength values to resin bonding materials (24).
The reason to use HF in a liquid state was to eliminate the influence of the thickening agent present in the available commercial HF products, as they could impair the movement/collisions of agitated HF molecules to the EMX. Thus, by not using a thickening agent, it was possible to properly assess the idea/concept of heating treatments more clearly.

Small specimens were used in the current study to decrease the probability of cohesive failures within the resin cement (14) due to the presence of a smaller bonding area. Thus, the necessary load to "break" the interface may be lower than the ultimate tensile strength of the resin cement, which may decrease the odds of cohesive failure. Also, fewer internal flaws may exist within lower bonding areas, such as bubbles that may predispose to cohesive failure. Even with increased $\mu$ SBS values, the failure pattern tended to be mostly adhesive. It may be assumed, according to the present results, that adhesive failure does not always indicate a poor quality bond, but that the interfacial bond strength has truly been assessed/ quantified (25).

One might speculate that increasing the etching time would be enough to properly etch the lithium disilicate glass ceramic when using lower HF concentrations. To date, there are no reports that have specifically dealt with different $\mathrm{HF}$ concentrations and etching times on the bond strength of resin cement on EMX. Thus, the aim of this research was to provide ideal etching pattern/ bond strength in the shortest time possible in order to save clinical operative chair time using the lowest HF concentration.

A relevant point was reached with this study: temperature does have an influence on the etching pattern/bond strength when $5 \%$ hydrofluoric acid is considered the etching agent on lithium disilicate glass ceramic. Further discussions should be considered regarding the heat treatment methodologies, such as using lower temperatures, altered etching times, evaluating the EMX mechanical properties and the effects of aging on bond strength before considering the use of heat treatments for EMX etching procedures. Also, the biologic effect should be further discussed regarding the effect of different etching times and HF concentrations when dealing, or not, with previous heat treatments.

Hydrofluoric acid concentrations do have an influence on the bonding characteristics of lithium disilicate glass ceramic with $5 \% \mathrm{HF}$ resulting in lower $\mu \mathrm{SBS}$ and poorer glassy matrix dissolution when compared to $10 \% \mathrm{HF}$. The heat treatments enhanced the glassy matrix removal/ bond strength of $5 \% \mathrm{HF}$, producing similar behavior when compared to non-heat treated $10 \% \mathrm{HF}$, supporting that heating less concentrated HF could be used instead 
of higher concentrations when etching lithium disilicate glass ceramic is considered.

\section{Resumo}

0 objetivo deste estudo foi avaliar os efeitos das concentrações de ácido fluoridrico (AF) e do prévio tratamento térmico (PT) na morfologia da superficie e resistência de união ao microcisalhamento ( $\mu$ RUM) de uma cerâmica vítrea de dissilicato de lítio (EMX) ao cimento resinoso. Cento e quatro espécimes de EMX foram aleatoriamente distribuidos em dois grupos $(n=52)$ de acordo com a concentração do AF: $5 \%$ e $10 \%$. Os espécimes foram novamente distribuidos de forma aleatória de acordo com o PTT ( $n=13)$ : controle (sem PTT); AF previamente aquecido $\left(70^{\circ} \mathrm{C}\right)$; superficie do EMX previamente aquecida $\left(85^{\circ} \mathrm{C}\right)$; combinação entre $\mathrm{AF}$ e EMX aquecidos. 0 tempo de condicionamento foi fixado em $20 \mathrm{~s}$. Todos os espécimes de EMX foram silanizados e receberam a aplicação de uma fina camada de um adesivo sem carga. Cinco cilindros de cimento resinoso foram confeccionados usando tubos Tygon como matrizes e então armazenados por $24 \mathrm{~h}$ a $37^{\circ} \mathrm{C}$. Uma amostra condicionada de cada grupo foi aleatoriamente selecionada e analisada em um microscópio eletrônico de varredura em emissão de campo (MEVEC). Os dados foram submetidos ao teste ANOVA de dois fatores e múltiplas comparações foram feitas pelo teste de Tukey $(\alpha=0.05)$. Para os grupos controle, AF $5 \%$ mostrou valor de $\mu$ RUM estatisticamente menor do que AF 10\% ( $<<0.05)$. PT aumentou os valores de $\mu \mathrm{RUM}$ para o $\mathrm{AF} 5 \%$, proporcionando resultados estatisticamente similares ao grupo AF $10 \%$ controle $(p<0.05)$. MEVEC mostrou um aumento na remoção da matriz vitrea quando o PTा foi aplicado ao grupo AF 5\%, no entanto esse efeito não foi visto no grupo $\mathrm{AF} 10 \%$. 0 PTT tem o potencial de melhorar a resistência de união do AF $5 \%$ na cerâmica vitrea reforçada por disilicato de lítio.

\section{References}

1. Pieger S, Salman A, Bidra AS. Clinical outcomes of lithium disilicate single crowns and partial fixed dental prostheses: a systematic review. J Prosthet Dent 2014;112:22-30.

2. Edelhoff $D$, Brix 0 . All-ceramic restorations in different indications: a case series. J Am Dent Assoc 2011;142:14S-9S.

3. Höland $W$, Schweiger $M$, Frank $M$, Rheinberger. A comparison of the microstructure and properties of the IPS Empress 2 and the IPS Empress glass-ceramics. J Biomed Mater Res 2000;53:297-303.

4. Lin WS, Zandinejad A, Metz MJ, Harris BT, Morton D. Predictable restorative work flow for computer-aided design/computer-aided manufacture-fabricated ceramic veneers utilizing a virtual smile design principle. Oper Dent 2015;40:357-363.

5. Lin WS, Harris BT, Ozdemir E, Morton D. Maxillary rehabilitation with a CAD/CAM-fabricated, long-term interim and anatomic contour definitive prosthesis with a digital workflow: a clinical report. J Prosthet Dent 2013;110:1-7.

6. Moshaverinia A, Torbati A, Kar K, Aalam AA, Takanashi K, Chee WW. Full mouth rehabilitation of a young patient with partial expressions of ectodermal dysplasia: a clinical report. J Prosthet Dent 2014;112:449454.

7. Tian T, Tsoi JK, Matinlinna JP, Burrow MF. Aspects of bonding between resin luting cements and glass ceramic materials. Dent Mater 2014;30:e147-e162.
8. Sundfeld Neto D, Naves LZ, Costa AR, Correr AB, Consani S, Borges $\mathrm{GA}$, et al.. The effect of hydrofluoric acid concentration on the bond strength and morphology of the surface and interface of glass ceramics to a resin cement. Oper Dent 2015;40:470-479.

9. Blatz MB, Sadan A, Kern M. Resin-ceramic bonding: A review of the literature. J Prosthet Dent 2003;89:268-274.

10. Brum R, Mazur R, Almeida J, Borges G, Caldas D. The influence of surface standardization of lithium disilicate glass ceramic on bond strength to a dual resin cement. Oper Dent 2011;36:478-485.

11. Guarda $G B$, Correr $A B$, Gonçalves LS, Costa AR, Borges GA, Sinhoreti $M A$, et al.. Effects of surface treatments, thermocycling, and cyclic loading on the bond strength of a resin cement bonded to a lithium disilicate glass ceramic. Oper Dent 2013;38:208-217.

12. Kalavacharla V, Lawson N, Ramp L, Burgess J. Influence of etching protocol and silane treatment with a universal adhesive on lithium disilicate bond strength. Oper Dent 2015;40:372-378.

13. Menees TS, Lawson NC, Beck PR, Burgess J0. Influence of particle abrasion or hydrofluoric acid etching on lithium disilicate flexural strength. J Prosthet Dent 2014;112:1164-1170.

14. Lise DP, Perdigão J, Van Ende A, Zidan 0, Lopes GC. Microshear bond strength of resin cements to lithium disilicate substrates as a function of surface preparation. Oper Dent 2015;40:524-532.

15. Xiaoping L, Dongfeng R, Silikas N. Effect of etching time and resin bond on the flexural strength of IPS e.max Press glass ceramic. Dent Mater 2014;30:e330-e336.

16. Zogheib LV, Bona AD, Kimpara ET, McCabe JF. Effect of hydrofluoric acid etching duration on the roughness and flexural strength of a lithium disilicate-based glass ceramic. Braz Dent J 2011;22:45-50.

17. Casucci A, Monticelli F, Goracci C, Mazzitelli C, Cantoro A, Papacchini $\mathrm{F}$, et al.. Effect of surface pre-treatments on the zirconia ceramic-resin cement microtensile bond strength. Dent Mater 2011;27:1024-1030.

18. Casucci A, Mazzitelli C, Monticelli F, Toledano M, Osorio R, Osorio E, et al.. Morphological analysis of three zirconium oxide ceramics: Effect of surface treatments. Dent Mater 2010;26:751-760.

19. Casucci A, Osorio E, Osorio R, Monticelli F, Toledano M, Mazzitelli C, et al.. Influence of different surface treatments on surface zirconia frameworks. J Dent 2009;37:891-897.

20. Liu D, Tsoi JK, Mantilinna JP, Wong HM. Effects of some chemical surface modifications on resin zirconia adhesion. J Mech Behav Biomed Mater 2015;46:23-30.

21. Ozcan M, Allahbeickaragui A, Dündar M. Possible hazardous effects of hydrofluoric acid and recommendations for treatment approach: a review. Clin Oral Investig 2012;16:15-23.

22. Dill KA, Bromberg S. Molecular Driving Forces: Statistical Thermodynamics in Chemistry and Biology. 1st ed. New York, New York; 2002.

23. Pilliing MJ, Seakins PW. Reaction Kinetics. 2nd ed. Oxford University Press Inc., New York; 1995.

24. Naves LZ, Soares CJ, Moraes RR, Gonçalves LS, Sinhoreti MA, CorrerSobrinho L. Surface/interface morphology and bond strength to glass ceramic etched for different periods. Oper Dent 2010;35:420-427.

25. Della Bona A, Anusavice KJ, Mecholsky Jr JJ. Failure analysis of resin composite bonded to ceramic. Dent Mater 2003;19:693-699. 